\title{
IMPERFECT ENFORCEMENT, FOREIGN INVESTMENT, AND FOREIGN AID
}

\author{
Elizabeth Asiedu \\ University of Kansas
}

\author{
AnNe P. Villamil \\ University of Illinois at Urbana-Champaign
}

The lack of a supranational legal authority that can enforce private contracts across borders makes debt repayment in an international setting contingent on borrowers' willingness to pay rather than ability to pay. This market failure (i.e., inadequate enforcement) causes investment to fall short of its unconstrained level. This paper examines how foreign aid affects a country's willingness to honor private investment agreements. We consider two types of aid: technical assistance and loan subsidies. We show that when enforcement is inadequate, aid has the following effects: (i) it reduces default risk, promotes capital flows, and can, in principle, restore investment to its unconstrained level; (ii) when default risk is high, aid can increase the welfare of both the recipient and the donor country. Thus, foreign aid serves as an enforcement mechanism in an international setting. This provides a nonaltruistic rationale for foreign aid. Finally, we discuss the implications of providing bilateral versus multilateral aid (e.g., by individual countries versus multilateral organizations).

Keywords: Enforcement, Foreign Aid, Foreign Investment, Multilateral Organizations

\section{INTRODUCTION}

Private capital flows to developing countries have grown significantly, increasing from $\$ 43$ billion in 1990 to $\$ 239$ billion in 1999 . As a consequence, some policy makers have called for a reduction in developmental lending-that is, subsidized loans from bilateral and multilateral agencies to developing countries. ${ }^{1}$ Others taking a more radical stand have called for the abolition of multilateral organizations such as the World Bank, arguing that "the market" will direct capital flows appropriately. This argument is not new. According to Rodrik (1995), John McCloy, the World Bank's second president, believed that the Bank "would go out of business in due course because the long-term capital needed for development

Elizabeth Asiedu's research was funded by a grant from the University of Kansas's General Research Fund. We are grateful to Mohamed El-Hodiri, Donald Lien, and Jianbo Zhang for helpful comments. We are especially grateful to an Associate Editor for comments that improved the paper substantially. Address correspondence to: Anne P. Villamil, Department of Economics, University of Illinois, 1206 S. Sixth Street, Champaign, IL 61820, USA; e-mail: avillami@uiuc.edu. 
would eventually be provided by private investors." We analyze the role of foreign aid when enforcement of contracts is inadequate and underinvestment occurs as a result of this market failure. We consider two types of foreign aid-subsidized loans and technical assistance - and show that when enforcement is inadequate, these programs can mitigate the underinvestment problem and therefore provide a rationale for developmental assistance in conjunction with private markets.

One of the crucial problems pertaining to international lending is the lack of a supranational legal authority that can enforce private contracts across borders. As a result, foreign capital is subject to endogenous expropriation risk: Borrowers may simply choose not to repay their debt. ${ }^{2}$ In a seminal paper, Eaton and Gersovitz (1981) showed that underinvestment results. Because an effective supranational judicial system with the authority to enforce contracts is unlikely, we consider policy interventions that mitigate the underinvestment problem. As is standard in the literature, a country is cut off from future credit transactions if it defaults on a loan. When agents discount the future highly, even this severe punishment is not strong enough to deter default. A number of studies have examined the extent to which additional punishments can sustain lending. ${ }^{3}$ The most common penalty is that a default results in interference with the international transactions of the debtor; for example, the lender may impose trade sanctions or seize the debtor's foreign assets [e.g., Cohen and Sachs (1986) and Bulow and Rogoff (1989)]. These penalties have two major disadvantages. First, the size of the penalty is exogenous and therefore does not depend on the characteristics of debtors or creditors. Second, the sovereignty status of countries limits the extent to which countries can be "punished" for defaulting.

Given the limitations of direct punishments, an alternative solution is to reward borrowers for good behavior - that is, if they repay the debt. This paper examines the extent to which a particular type of reward, foreign aid, affects the incentive of the recipient country to expropriate foreign investment. We consider a two-country model in which a "rich" country lends to a "poor" country. In addition, the rich country can provide aid to the poor country. If the poor country defaults on a loan, it loses access to foreign capital and aid. By increasing the cost of default, aid reduces default risk and promotes private foreign investment. Furthermore, we show that it is possible for the donor country to benefit, along with the recipient country, from giving aid when enforcement of private contracts is imperfect. Specifically, we show that it is at least weakly Pareto improving for a rich country to provide foreign aid to a risky poor country with investment opportunities when there is no supranational court that can compel repayment. ${ }^{4}$ The key insight is that, when enforcement is problematic, foreign aid serves as an implicit enforcement mechanism that benefits both the donor and the recipient country. ${ }^{5}$

In deriving our results, we use a model of imperfect enforcement in which the foreign investment problem is reduced to a comparison of a country's idiosyncratic discount factor $\beta$ and two critical thresholds, $\beta$ and $\beta^{*}$ [cf., Asiedu and Villamil (2000)]. These thresholds yield disjoint subintervals that correspond to three possible equilibria: autarky, constrained, and unconstrained optimal investment. 
We focus on policy interventions that can alter the thresholds, thereby increasing the likelihood that a country can access private capital markets. This approach is closely related to recent work on self-enforcing contracts by Atkeson (1991), Eaton (1993), Thomas and Worrall (1994), and Krasa and Villamil (2000).

Section 2 specifies the model and describes the equilibria without aid. Section 3 analyzes the impact of aid on capital flows and provides estimates of model parameters. Section 4 concludes.

\section{BASIC MODEL AND EQUILIBRIA}

Consider a world with an infinite time horizon and two countries, rich and poor, that are distinguished by the size of their capital stocks and investment opportunities. The poor country has capital stock, $k_{t}^{p}=k^{p}$ for all $t$, that is less than the optimal amount. It neither invests abroad nor can its capital stock be augmented. The rich country has an elastic capital stock $k_{t}^{r}=k^{r}$ for all $t$. The rich country can invest abroad at gross rate of return $r$ or in a safe alternative storage technology with gross return $\sigma$. There is no intrinsic difference between capital in the two countries, and $k^{p}+k^{r}$ is the world capital stock. See Smith and Villamil (1998) for a model with differential access to alternative investment opportunities. Financial repression can limit access to outside investment opportunities in developing countries [cf., Bencivenga and Smith (1992)].

Agents from both countries have a common risk-neutral utility function. ${ }^{6}$ The key friction in the model is that the capital-poor country may choose not to repay its debt: The government in the capital-poor country may prevent its citizens from honoring foreign contractual obligations, for example, by blocking access to foreign exchange or by reneging on loan guarantees. Then, if the rich country lends to the poor country at gross return $r$, it may not be repaid. The alternative storage technology to which only the rich country has access has a certain but lower gross return $\sigma$, where $r>\sigma>0$. Investors in the rich country would like to lend as much as possible to the poor country, but the level of investment may be constrained by default risk. ${ }^{7}$

The poor country has a constant-returns-to-scale production function, $F(\cdot)$, which requires two inputs, labor and capital. Let $f(\cdot)$ denote output per capita, which satisfies the Inada conditions. The domestic capital stock is less than the optimal capital stock; thus, $f^{\prime}\left(k^{p}\right)>r$. Let $k_{t}$ be the total amount of capital used by the poor country for production in period $t$. Each period $t$, the poor country borrows $\left(k_{t}-k^{p}\right)$ from abroad and combines it with domestic capital $k^{p}$ for production. Assume that the rich country's capital stock exceeds the optimal amount of capital needed for production; thus, $f^{\prime}\left(k^{r}\right)<r .{ }^{8}$ At the end of the period, the country chooses whether to 9

- repay its debt, $r\left(k_{t}-k^{p}\right)$ : Consume $y_{t}=f\left(k_{t}\right)-r\left(k_{t}-k^{p}\right)$, and borrow again the next period; or

- default: Consume $f\left(k_{t}\right)$, and receive no foreign capital henceforth (i.e., $k_{s}=k^{p}$, for $s>t$ ). 
The poor country's present discounted utility of income is $W_{t}=\sum_{s=t}^{\infty} \beta^{s-t} y_{s}$ with $0<\beta<1$ and $U^{p}=y_{t}=f\left(k_{t}\right)-r\left(k_{t}-k^{p}\right)$. As is standard [cf., Yaari (1965)], $\beta$ is the discount factor with $\beta=\theta \rho$. Parameter $\theta$ denotes the probability of survival, an idiosyncratic factor that reflects the "patience" of decisionmakers in the poor country, and $\rho=1 / r$ is the common pure discount factor. As $\theta$ falls, the "countryspecific" $\beta$ falls, indicating that the country becomes more myopic. ${ }^{10}$ The rich country's utility in period $t$ is $U^{r}\left(k_{t}\right)=r\left(k_{t}-k^{p}\right)+\sigma\left[k^{r}-\left(k_{t}-k^{p}\right)\right]$. The first term is the gross return on capital lent to the poor country and the second term is the gross return on capital put in storage.

Whether the poor country will repay a loan is governed by an incentive constraint. The discounted present value from being "bad" and reneging on a loan in period $t$ and remaining autarkic thereafter is given by

$$
B\left(k_{t}\right)=f\left(k_{t}\right)+\sum_{s=t+1}^{\infty} \beta^{s-t} y_{s}=f(k)+\frac{\beta}{1-\beta} f\left(k^{p}\right) .
$$

The discounted present value of being "good" and honoring a contract in period $t$ and maintaining access to foreign investment is given by

$$
G\left(k_{t}\right)=\sum_{s=t}^{\infty} \beta^{s-t}\left[f\left(k_{s}\right)-r\left(k_{s}-k^{p}\right)\right]=\frac{1}{1-\beta}\left[f(k)-r\left(k-k^{p}\right)\right] .
$$

As a consequence of stationarity, $B(k)$ and $G(k)$ are time invariant. The poor country will repay the loan if

$$
B(k) \leq G(k), \quad \forall k
$$

Whether a rich country with an outside option will lend to the poor country is governed by a voluntary participation constraint. The rich country must receive at least the return available from the storage technology. That is,

$$
r\left(k_{t}-k^{p}\right)+\sigma\left[k^{r}-\left(k_{t}-k^{p}\right)\right] \geq \sigma k^{r} .
$$

Clearly, (2) is satisfied whenever $r>\sigma$, as assumed in the model.

The social planner's problem is to choose a stationary level of aggregate investment $k$ to maximize $W(k)$ subject to repayment incentive constraint $(1)$ and participation constraint (2).

Problem 1. Choose $k$ to maximize

$$
W(k)=\frac{1}{1-\beta}\left[f(k)-r\left(k-k^{p}\right)\right]
$$

subject to (1) and (2).

Note that (2) does not bind. In a similar model without an outside option, Asiedu and Villamil (2000) show that, when (1) holds, contracts are self-enforcing, that is, 
honored voluntarily. Let $\lambda$ be the LaGrange multiplier. The first-order conditions are $B(k)=G(k)$ and

$$
f^{\prime}(k)-r=\frac{r \lambda(1-\beta)}{1+\lambda \beta} .
$$

When enforcement is imperfect, the poor country's specific characteristics $k^{p}$ and $\beta(\theta, r)$ determine, in conjunction with $r$, its ability to attract foreign investment. In contrast, when enforcement is perfect, $r$ is sufficient to determine capital flows, and the poor country receives the unconstrained optimal level of investment. As a consequence, the solutions to Problem 1 are described by one of three cases. Let $k_{u}^{*}$ denote the optimal capital sequence when (1) does not bind (the unconstrained optimal plan) and $k_{c}^{*}$ denote the plan when (1) binds (the constrained optimal plan). Then:

Case 1. $B(k)>G(k)$ for all $k>k^{p}$ : The constraint set is empty and no foreign investment occurs.

Case 2. The constraint binds (i.e., $\lambda>0$ ): $f^{\prime}(k)>r$ and $k=k_{c}^{*}$ is the optimal investment plan.

Case 3. The constraint does not bind (i.e., $\lambda=0)$ : $f^{\prime}(k)=r$ and $k=k_{u}^{*}$ is the optimal investment plan.

As in Asiedu and Villamil (2000), the solutions to Problem 1 are characterized by restrictions on the discount factor that segment the unit interval into three cases. The equilibrium is determined by a comparison of $\beta$ and the relevant case on the unit interval. Define these two critical thresholds by

$\beta^{*}$ : the minimum discount factor required to sustain $k_{u}^{*}$, and

$\underline{\beta}$ : the minimum discount factor required to attract foreign investment.

Foreign investors effectively compare the poor country's idiosyncratic $\beta(\theta, r)$ and the relevant subinterval: Case 1 prevails when $\beta \in(0, \beta)$; Case 2 prevails when $\beta \in\left[\underline{\beta}, \beta^{*}\right]$; and Case 3 prevails when $\beta \in\left[\beta^{*}, 1\right]$.

The utilities of the two countries under the three cases are

Case 1: $U^{r}=\sigma k^{r}$, and $U^{p}=f\left(k^{p}\right)$;

Case 2: $U^{r}=r\left(k_{c}^{*}-k^{p}\right)+\sigma\left[k^{r}-\left(k_{c}^{*}-k^{p}\right)\right]$, and $U^{p}=f\left(k_{c}^{*}\right)-r\left(k_{c}^{*}-k^{p}\right)$;

Case 3: $U^{r}=r\left(k_{u}^{*}-k^{p}\right)+\sigma\left[k^{r}-\left(k_{u}^{*}-k^{p}\right)\right]$, and $U^{p}=f\left(k_{u}^{*}\right)-r\left(k_{u}^{*}-k^{p}\right)$.

For both countries the most preferred equilibrium is Case 3 and the least preferred is Case 1. Case 2 is a version of Kydland and Prescott's (1977) time inconsistency result: The constrained equilibrium is Pareto inferior relative to the unconstrained equilibrium with full commitment. However, no "commitment technology" is available that can induce agents to adhere to the "first best" intertemporal plan expost. The inability of the poor country to commit to honor investment agreements has an adverse impact on both. This provides an incentive for the two countries to implement polices that will mitigate the enforcement problem. Asiedu and Villamil (2000) study policy options available to the poor country. In the next 
section we discuss policies that the rich country or a third party can use to ameliorate the inefficiencies that result from inadequate contractual enforcement. The class of policies that we consider affect the threshold discount factors, $\beta$ and $\beta^{*}$, but not the country-specific discount factor $\beta(\theta, r)$. We show that, by reducing $\beta$ and $\beta^{*}$, foreign aid can, in principle, eliminate the autarky equilibrium and restore equilibrium to the unconstrained level. Further, when the enforcement constraint binds, an increase in aid raises $k_{c}^{*}$.

\section{EXTERNAL ASSISTANCE}

In this section we analyze the impact of foreign aid on capital flows and welfare. We consider developmental finance, a type of foreign aid often provided by developedcountry governments and multilateral organizations. Development finance takes two forms: loan subsidy and technical assistance. We examine how these programs affect a country's incentive to default. All proofs are in the Appendix.

\subsection{Policy 1: Loan Subsidy}

Loan subsidies are an important source of finance for many developing countries. For example, over $90 \%$ of foreign loans to Sub-Saharan Africa are subsidized. These loans either carry below-market interest rates or take the form of grants (i.e., funds for which there is no repayment requirement). ${ }^{11}$ We modify the model so that, in addition to lending to the poor country, the rich country can provide aid in the form of a loan subsidy. The penalty for default is that the poor country loses access to foreign investment and aid. Since current output is consumed each period, aid must be injected each period in order to have the desired effect. This is consistent with the empirical results of Lensink and Morrissey (2000), which indicate that aid has a positive impact on investment only if aid receipts are predictable.

Let $0 \leq \gamma \leq 1$ be the fraction of capital provided by the rich country on a concessional basis at gross interest rate $\tau$. We assume that $0 \leq \tau<\sigma<r$. Thus, $\tau=0$ indicates that the loan is a grant (i.e., no interest or principal repayment is required). Similarly, $\tau=1$ indicates that the loan is interest free (only repayment of principal is required). Finally, $1<\tau<r$ indicates that the loan requires repayment of principal and interest at a concessional rate. We assume that $0 \leq \tau<\sigma<r$, which reflects the fact that providing aid is costly to the donor country since the donor would receive a higher return $\sigma$ if it utilized the storage facility. However, if the loan were repaid, the rich country would receive the highest return by investing in the poor country at market rate $r$. Then, the amount of loans provided at interest rate $\tau$ is $\gamma\left(k-k^{p}\right)$. The remaining outside investment, $(1-\gamma)\left(k-k^{p}\right)$, earns gross return $r$. The utility from default, $B(k)$, is unchanged. The utility from not defaulting, $G(k)$, is now given by

$$
G(k)=\frac{1}{1-\beta}\left[f(k)-r(1-\gamma)\left(k-k^{p}\right)-\tau \gamma\left(k-k^{p}\right)\right] .
$$


To examine the impact of Policy 1 on the two countries, we solve two problems. Problem 2 solves the poor country's problem by choosing the level of investment, $k$, that maximizes its utility for a given loan package, $w=w(\tau, \gamma)$, while Problem 3 solves the rich country's problem by specifying the level of aid that maximizes its utility, given that $k$ solves Problem 2.

Problem 2. For a given loan package, $w=w(\tau, \gamma)$, choose $k$ to maximize

$$
W(k)=\frac{1}{1-\beta}\left[f(k)-r(1-\gamma)\left(k-k^{p}\right)-\tau \gamma\left(k-k^{p}\right)\right]
$$

subject to

$$
B(k) \leq G(k), \quad \forall k .
$$

Similar to Problem 1, the equilibrium level of investment is described by three cases. We next examine how Policy 1 affects the threshold discount factors, capital flows, and the welfare of the poor country. We show that, by the appropriate choice of policy, a loan subsidy program can eliminate the Case 1 and Case 2 equilibria. Further, when the enforcement constraint binds, a loan subsidy raises utility and foreign investment. Claim 1 summarizes the results.

Claim 1. Loan subsidies have the following effects:
(a) $\frac{d \underline{\beta}}{d \gamma}<0$ and $\frac{d \beta^{*}}{d \gamma}$ is unclear;
(b) $\frac{d \underline{\beta}}{d \tau}>0$ and $\frac{d \beta^{*}}{d \tau}>0$;

$$
\text { (c) } \frac{d k_{c}^{*}}{d \gamma}>0 \text { and } \frac{d y_{c}^{*}}{d \gamma}>0 \text {; }
$$
(d) $\frac{d k_{c}^{*}}{d \tau}<0$ and $\frac{d y_{c}^{*}}{d \tau}<0$.

(ii)

(iii) There exists a loan package $\bar{w}=w(\bar{\tau}, \bar{\gamma})$ that eliminates the autarky equilibrium.

(iv) There exists a loan package $w^{*}=w\left(\tau^{*}, \gamma^{*}\right)$ that restores investment to its unconstrained level.

Discussion. Claim 1 indicates that a concessionary loan subsidy policy (i.e., Policy 1) weakens the incentive constraint and expands investment. The policy tends to decrease the critical thresholds, $\beta$ and $\beta^{*}$, which determine the lengths of the intervals that correspond to the three equilibrium cases. When policy reduces the critical thresholds, this shrinks the Case 1 and Case 2 equilibria, thereby expanding the "best-case" unconstrained Case 3 equilibrium. Claim 1(i) indicates that, when the donor increases the size of the loan package $\gamma$, this decreases $\beta$, reducing the Case 1 interval. The effect of $\gamma$ on $\beta^{*}$ is unclear, ${ }^{12}$ but Claim 1(ii) shows that an increase in $\gamma$ always leads to more investment in the constrained case. Claim 1(ii) also shows that the utility of the poor country and foreign investment decrease with $\tau .{ }^{13}$ Finally, Claims 1(iii) and 1(iv) indicate that, by lowering the threshold discount factors to the point where the country-specific $\beta$ exceeds the threshold, Policy 1 can eliminate the undesirable Case 1 and Case 2 equilibria.

Numerical Example. Consider the case in which the loan takes the form of a grant, that is, $\tau=0$. Table 1 shows that in the absence of aid the autarky (Case 1) equilibrium prevails and no foreign investment occurs. This occurs because $\beta=0.62<\underline{\beta}=0.699$. An increase in $\gamma$ to 0.3 lowers $\underline{\beta}$ and $\beta^{*}$ such that 
TABLE 1. Effect of a grant on the equilibrium ${ }^{a}$

\begin{tabular}{lccc}
\hline & $\begin{array}{c}\gamma=0: \text { No aid } \\
\text { Case 1 }\end{array}$ & $\begin{array}{c}\gamma=0.3 \\
\text { Case 2 }\end{array}$ & $\begin{array}{c}\gamma=0.6 \\
\text { Case 3 }\end{array}$ \\
\hline$\underline{\beta}$ & 0.699 & 0.489 & 0.280 \\
$\beta^{*}$ & 0.845 & 0.728 & 0.598 \\
$k_{c}^{*}-k^{p}$ & 0 & 0.061 & 0.207 \\
$y_{c}^{*}$ & 1.316 & 1.42 & 1.701 \\
\hline${ }^{a}$ Parameters: $r=1.05, \tau=0, \beta=0.62, k=0.1002$, and $f(k)=k^{0.3}$.
\end{tabular}

$\beta \in\left(\underline{\beta}, \beta^{*}\right)$, and the constrained equilibrium (Case 2) prevails. When $\gamma$ increases to $0 . \overline{6}, \beta \in\left(\beta^{*}, 1\right)$ and the unconstrained equilibrium (Case 3 ) prevails. Thus, loan package $\bar{w}=w(0,0.3)$ eliminates the autarky equilibrium and $w^{*}=w(0,0.6)$ eliminates the constrained equilibrium. Further, $k_{c}^{*}$ and $y_{c}^{*}$ increase with $\gamma$.

Claim 1 shows that a loan subsidy unambiguously benefits the poor country. However, this program is costly to the rich country because the concessional interest rate, $\tau$, is less than the return on storage, $\sigma$. As a consequence, a nonaltruistic rich country will provide a loan subsidy only if doing so is at least weakly Pareto improving compared to the outcome without aid. This raises the following questions:

- Under what conditions will the rich country benefit (along with the poor country) from giving a loan subsidy?

- What is the optimal loan package (i.e., how are $\gamma$ and $\tau$ determined)?

To answer these questions we analyze the impact of Policy 1 on the welfare of the rich country when the Case 1 and Case 2 equilibria occur. We first consider the Case 1 equilibrium in which the poor country's $\beta$ is so low that no foreign investment occurs. We derive necessary and sufficient conditions under which a loan subsidy yields a strict Pareto improvement for the rich country. The results are summarized in Proposition 1. We next derive the optimal loan package in which the Case 2 equilibrium prevails. The results are stated in Proposition 2.

The utility of the rich country is given by

$$
U^{r}(\gamma, \tau)=r(1-\gamma)\left(k-k^{p}\right)+\tau \gamma\left(k-k^{p}\right)+\sigma\left[k^{r}-\left(k-k^{p}\right)\right],
$$

where $k=k(\gamma, \tau)$ solves Problem 2. The first term is the rich country's gross return on nonsubsidized investment in the poor country; the second term is the gross return on subsidized loans; the last term is the amount of capital that the rich country invests in storage and earns gross return $\sigma$. In the Case 1 equilibrium, $k=k^{p}$, and in the Case 2 equilibrium, $k$ satisfies $G(k)=B(k)$.

PROPOSITION 1. Suppose the poor country's discount factor is too low [i.e., $\left.\beta<\underline{\beta}\left(r, k^{p}\right)\right]$ and therefore the autarky equilibrium is attained. Then, a loan package, $\hat{w}=w(\hat{\gamma}, \hat{\tau})$, yields a strict Pareto improvement relative to autarky for the rich country if and only if $\hat{w}$ satisfies the following conditions: 
(i) $\beta \geq \underline{\beta}\left(r, k^{p}, \hat{w}\right)=[r(1-\hat{\gamma})+\hat{\tau} \hat{\gamma}] / f^{\prime}\left(k^{p}\right)$;

(ii) $\hat{\gamma}(r-\hat{\tau})<(r-\sigma)$.

Let $w^{*}=\left(\gamma^{*}, \tau^{*}\right)$ be the optimal loan package that maximizes $U^{r}(w)$. In determining $w^{*}$, we first assume an interior solution (i.e., $\gamma>0$ ) and solve Problem 3 , and then compare the utility under aid with the utility without aid.

Problem 3. Choose $\gamma>0$ and $0 \leq \tau<\sigma$ to maximize

$$
U^{r}(\tau, \gamma)=r(1-\gamma)\left(k_{c}^{*}-k^{p}\right)+\tau \gamma\left(k_{c}^{*}-k^{p}\right)+\sigma\left[k^{r}-\left(k_{c}^{*}-k^{p}\right)\right],
$$

where $k_{c}^{*}=k_{c}^{*}(\tau, \gamma)$ solves Problem 2 .

PROPOSITION 2. Suppose the poor country's discount factor is moderate \{i.e., $\left.\beta \in\left[\beta, \beta^{*}\right)\right\}$ and therefore the constrained equilibrium prevails. Then the optimal loan package $w^{*}=\left(\gamma^{*}, \tau^{*}\right)$ is unique and satisfies the rich country's utility $U^{r}\left(w^{*}\right)=\max \left\{U^{r}(0), U^{r}(\tilde{w})\right\}$ where $\tilde{w}=(\tilde{\gamma}, \tilde{\tau})$ solves Problem 3 and $U^{r}(0)$ is the utility with no aid.

Proposition 1 specifies necessary and sufficient conditions under which a loan subsidy program is welfare enhancing when the autarky equilibrium prevails. Condition (i) indicates that, in the autarky equilibrium, the rich country will invest in the poor country only if it can provide enough aid such that the poor country's $\beta$ achieves the lower threshold (i.e., $\beta \geq \underline{\beta}$ ). The reason is that, when $\beta<\beta$, the gain from expropriation exceeds the cost. As a consequence the poor country will expropriate foreign investment. Condition (ii) ensures that aid yields a higher utility than autarky. Proposition 2 indicates that when the repayment incentive constraint binds, the optimal loan package yields at least weak Pareto improvements to the rich country, compared to the outcome without aid.

\subsection{Policy 2: Technical Assistance}

Developed countries and multilateral agencies often provide free technical assistance to developing countries in the form of technical cooperation grants. ${ }^{14}$ These grants take two forms: freestanding grants, which are intended to finance the transfer of technical and managerial skills for the purpose of building national capacity without reference to any specific investment project; and investment-related technical assistance, which is provided to strengthen the capacity to execute specific investment projects. Given the nature of technical assistance, it is reasonable to assume that these services increase productivity and therefore result in higher output. We modify our model to allow the rich country to provide technical assistance to the poor country. Then, the penalty for default is twofold: The poor country loses access to foreign investment and technical assistance. ${ }^{15}$

Let $\alpha$ be the amount of resources that the rich country spends on technical assistance. Suppose that technical assistance causes the poor country's output to increase by $\delta(\alpha) .{ }^{16}$ Assume $\delta^{\prime}(\alpha)>0$ and $\delta^{\prime \prime}(\alpha)<0$. Then, the utility from defaulting, $B(k)$, and the utility from not defaulting, $G(k)$, are given by 


$$
G(k)=\frac{1}{1-\beta}\left\{[1+\delta(\alpha)] f(k)-r\left(k-k^{p}\right)\right\},
$$

and

$$
B(k)=[1+\delta(\alpha)] f(k)+\frac{\beta}{1-\beta} f\left(k^{p}\right) .
$$

Next, we analyze the impact of technical assistance on the threshold discount factors, private capital flows, and the welfare of the two countries, and also discuss how $\alpha$ is selected.

Claim 2. Technical assistance has the following effects:

(i) It eliminates the autarky equilibrium.

(ii) When the incentive constraint binds,

$$
\frac{d k_{c}^{*}}{d \alpha}>0 ; \quad \frac{d y_{c}^{*}}{d \alpha}>0
$$

and $\mathrm{d} \beta^{*} / \mathrm{d} \alpha$ is unclear.

(iii) There exists some level of technical assistance, $\hat{\alpha}$, that will eliminate the constrained equilibrium.

Claim 2(i) indicates that countries that receive technical assistance will receive some foreign investment, although the level of investment may be constrained. This implies that $\beta=0$, suggesting that this type of policy may be especially useful in countries with inadequate enforcement, that is, low- $\beta$ countries. Claim 2(ii) suggests that "constrained countries" that receive technical assistance will attract more private foreign investment. Claim 2(iii) indicates that technical assistance can move a country from the constrained to the unconstrained equilibrium.

We now derive the optimal level of technical assistance and the conditions under which technical assistance yields Pareto improvements to the rich country. The utility of the rich country under this policy is given by

$$
U^{r}(\alpha)=r\left(k_{c}^{*}-k^{p}\right)+\sigma\left[k^{r}-\left(k_{c}^{*}-k^{p}\right)-\alpha\right],
$$

where $k_{c}^{*}=k_{c}^{*}(\alpha)$ solves the poor country's problem. The first term in the utility function is the gross return from investing abroad and the second term is the gross return from using the storage facility after paying for technical assistance.

PROPOSITION 3. Suppose the poor country's discount factor is too low [i.e., $\beta \in(0, \underline{\beta})]$ and therefore the autarky equilibrium is attained. Then technical assistance, $\alpha$, yields strict Pareto improvements to the rich country compared to the case without aid if and only if $\alpha \sigma<(r-\sigma)\left(k_{c}^{*}-k^{p}\right)$.

Problem 4. Choose $\alpha>0$ to maximize the rich country's utility:

$$
U^{r}(\alpha)=r\left(k_{c}^{*}-k^{p}\right)+\sigma\left[k^{r}-\left(k_{c}^{*}-k^{p}\right)-\alpha\right],
$$

where $k_{c}^{*}=k_{c}^{*}(\alpha)$ solves the poor country's problem. 
PROPOSITION 4. Suppose the poor country's discount factor is moderate \{i.e., $\left.\beta \in\left[\underline{\beta}, \beta^{*}\right)\right\}$ and therefore the constrained equilibrium prevails. Then the optimal level of technical assistance, $\alpha^{*}$, satisfies the rich country's utility $U^{r}\left(\alpha^{*}\right)=$ $\max \left\{U^{r}(0), U^{r}(\tilde{\alpha})\right\}$, where $\tilde{\alpha}$ solves Problem 4 and $U^{r}(0)$ is the utility when no aid is given.

Our analysis indicates that bilateral aid promotes foreign investment and unambiguously improves the welfare of the poor country. Further, the rich country can choose the level of aid such that it provides at least weak Pareto improvements compared to the case without aid. Why should multilateral assistance exist in a world in which governments have their own bilateral aid programs? Next, we make a case for multilateral assistance.

\subsection{Multilateral Assistance}

Our analysis indicates that the threat of losing access to bilateral aid in the event of default increases the penalty of default and, as a result, decreases default risk. This suggests that a lender may provide aid to a borrower as a means of protecting the lender's investment. However, uncoordinated bilateral aid has two important problems relative to multilateral aid. First, a "threshold problem" is inherent in the foreign aid equilibrium. That is, if a single lender cannot provide sufficient assistance to decrease $\underline{\beta}$ to the point where $\beta \geq \underline{\beta}$, it is preferable for the lender to provide no funds. This problem corresponds exactly to the "minimum finance constraint" in the Diamond (1984) and Williamson (1986) type of delegated monitoring models in which more than one investor is required to finance a project. In our model, if $\beta$ is very low, several investors may be necessary to provide sufficient funds to avoid the autarky equilibrium because the required aid may exceed a single rich country's resources. If this occurs, both countries will be stuck in the "bad" equilibrium. In contrast, by pooling resources a multilateral agency will have a bigger aid base to distribute and can coordinate aid more effectively among poor countries. ${ }^{17}$ Second, lack of coordination may provide an opportunity for selective default-a poor country may default on loans from one country and continue borrowing from other countries. If the motivation for providing aid is to reduce default risk, then it is more efficient for all countries to band together and form a coalition, that is, a multilateral agency. By coordinating official flows from multiple sources, the multilateral agency solves the threshold and selective default problems, and is able to take advantage of economies of scale and scope.

Finally, recall that foreign aid unambiguously improves the welfare of the poor country. Further, recall that bilateral aid is not motivated by altruism in our modelthe rich country provides aid only if doing so increases its utility. ${ }^{18}$ As we show in Propositions 1 and 3, this limits the amount of aid disbursed by the rich country. If an altruistic motive to alleviate poverty is also present, this will result in an increase in aid and thereby further enhance the poor country's welfare. ${ }^{19}$ Indeed, compared to multilateral loans, bilateral loans typically have higher interest rates and shorter repayment periods. Furthermore, bilateral assistance often take the 
form of tied credit - where the recipient country is required to use a specified amount of the loan to purchase goods and services manufactured by the donor country. The motivation for tied aid is to assist producers in the donor country and to reduce the net capital outflow generated by aid programs.

\subsection{Measures of Model Parameters}

Table 2 presents measures of key parameters in the model for selected poor countries. We use the interest-rate spread defined by the lending rate in the poor country minus LIBOR as a measure of $(r-\sigma)$; the ratio of technical assistance to GNP

TABLE 2. Model parameters for selected countries

\begin{tabular}{|c|c|c|c|c|c|c|}
\hline Country & $\begin{array}{l}\text { Discount } \\
\text { factor } \beta\end{array}$ & $\begin{array}{l}\text { Lending } \\
\text { rate minus } \\
\text { LIBOR } \\
r-\sigma\end{array}$ & $\begin{array}{c}\% \text { Technical } \\
\text { assistance/ } \\
\text { GNP, } \delta\end{array}$ & $\begin{array}{c}\% \text { of } \\
\text { Loans }^{a} \text { at } \\
\text { subsidized } \\
\text { rate } \gamma\end{array}$ & $\begin{array}{l}\text { Subsidized } \\
\text { interest } \\
\text { rate } \tau\end{array}$ & $\begin{array}{c}\text { Interest } \\
\text { on private } \\
\text { loans } r\end{array}$ \\
\hline Argentina & 0.62 & 6.1 & 0.06 & 43 & 6.99 & 7.99 \\
\hline Bangladesh & 0.36 & 8.6 & NA & 95 & 1.16 & 3.78 \\
\hline Brazil & 0.67 & NA & 0.05 & 40 & 6.99 & 8.48 \\
\hline Burkina Faso & 0.47 & NA & 5.11 & 100 & 1.27 & NA \\
\hline Cameroon & 0.55 & 14.4 & 1.3 & 93 & 4.29 & 7.83 \\
\hline Chile & 0.65 & 12.8 & 0.11 & 68 & 6.13 & 7.00 \\
\hline China & 0.66 & 4.1 & 0.09 & 33 & 5.44 & 7.03 \\
\hline Colombia & 0.57 & 34.8 & NA & 39 & 7.03 & 7.98 \\
\hline Congo & 0.42 & 14.4 & 1.22 & 100 & 5.36 & NA \\
\hline Ghana & 0.59 & NA & 1.49 & 81 & 1.73 & 7.20 \\
\hline Haiti & 0.23 & 16.6 & 3.01 & 100 & 1.42 & NA \\
\hline India & 0.58 & 9.2 & 0.14 & 67 & 3.88 & 7.14 \\
\hline Indonesia & 0.62 & 16.4 & NA & 69 & 5.29 & 6.76 \\
\hline Malaysia & 0.61 & 3.3 & 0.20 & 21 & 5.47 & 7.00 \\
\hline Mexico & 0.67 & 28.3 & 0.03 & 37 & 7.58 & 7.34 \\
\hline Niger & 0.43 & NA & 5.08 & 82 & 1.64 & 12.20 \\
\hline Nigeria & 0.47 & 14.8 & 0.35 & 82 & 5.58 & 7.78 \\
\hline Peru & 0.49 & 28 & 0.36 & 97 & 6.16 & 6.85 \\
\hline Philippines & 0.46 & 10 & 0.57 & 64 & 5.08 & 6.53 \\
\hline Russia & NA & NA & NA & 72 & 6.46 & 7.44 \\
\hline Sierra Leone & 0.32 & NA & 3.56 & 98 & 1.26 & 7.95 \\
\hline Swaziland & NA & 13 & 2.97 & 100 & 4.83 & NA \\
\hline Togo & 0.43 & NA & NA & 100 & 0.90 & NA \\
\hline Zambia & 0.42 & NA & 4.38 & 89 & 1.84 & 8.38 \\
\hline
\end{tabular}

Source: World Bank (2000). Data are averaged from 1988-1998.

${ }^{a}$ Subsidized loans are loans from developed-country governments, the World Bank, Regional Development Banks (African Development Bank, Asian Development Bank, and Inter-American Development Bank) and other multilateral agencies. These loans take the form of grants (i.e., have no repayment requirement) or carry below-market rates. Private loans include loans from commercial banks and other private creditors. The data indicate that subsidized loans are an important source of finance for low- $\beta$ countries. 
measures the level of output lost when technical assistance is withdrawn, $\delta$; the interest rate on private (i.e., nonsubsidized) foreign loans is $r ; \gamma$ and $\tau$ are the ratio of subsidized loans to total loans and the subsidized interest rates, respectively. The discount factor, $\beta=\theta / r$, where $\theta$ measures country risk, is given by the average of five indicators: corruption, contract repudiation, expropriation risk, rule of law, and bureaucratic quality. ${ }^{20}$

Discussion. Our model shows that foreign aid reduces default risk, stimulates foreign investment, and can improve the welfare of both the donor and the recipient country. Further, it may be more efficient to have one organization-a multilateral agency - coordinate aid disbursement. In this sense, multilateral agencies serve as an enforcement mechanism in an international setting, thereby providing a rationale for the existence of such organizations. The relationship between default risk and aid has already been established in the empirical literature [cf., Eaton and Gersovitz (1981), Burton and Inoue (1987), Nunnekamp and Picht (1989), Collier and Dollar (1998), Dollar and Easterly (1998)]. For example, using data for 53 developing countries, Nunnekamp and Picht (1989) conclude that countries that received more subsidized loans were less likely to engage in willful default.

Our model has the following implications for policy:

First, low- $\beta$ countries should receive more aid. ${ }^{21}$ For example, the correlation between $\beta$ and aid policy variables for the selected poor countries in Table 2 are $\operatorname{Corr}(\beta, \delta)=-0.7 ; \operatorname{Corr}(\beta, \gamma)=-0.8$, and $\operatorname{Corr}(\beta, \tau)=0.7$. The high correlation stems from the fact that default risk is higher for low- $\beta$ countries and, as a consequence, such countries are more likely to be in the autarky or constrained equilibrium. At a glance, this policy seems problematic because it suggests that the multilateral agency rewards countries with inefficient institutions (i.e., low- $\beta$ countries), thereby creating moral hazard - that is, no incentive for countries to improve their institutions. Note, however, that a country's welfare also depends on $\beta$. Thus, a country must improve its institutions in order to reap the full benefits of aid. This explanation is consistent with the empirical results of Burnside and Dollar (2000), who find that aid induces growth only in countries with good institutions (i.e., high- $\beta$ countries). Thus, our model provides a plausible explanation for why a number of countries in Sub-Saharan Africa have not experienced significant growth, in spite of obtaining large amounts of aid. ${ }^{22}$ Indeed, the inability of aid to stimulate growth is one of the main criticisms of multilateral agencies such as the World Bank.

A second implication of our model is that, for low- $\beta$ countries, developmental lending is effective (i.e., reduces default risk and stimulates private foreign investment) only if it is big enough to lower $\beta$ to the point where $\beta \geq \beta$. Otherwise, the country will expropriate foreign investment. A number of countries have, in the past, refused to repay foreign loans. For example, in 1972 the new military government of Ghana repudiated all foreign debts, including loans from the IMF and the World Bank. This suggests that a multilateral agency must be selective in its lending and cognizant of a "default trap" problem. Indeed, the World Bank 
sometimes ceases lending to highly politically unstable countries (e.g., the World Bank until recently had suspended lending to Liberia and Sierra Leone).

Third, the country-specific discount factor, $\beta$, affects a country's incentive to expropriate foreign investment. As shown in Table $2, \beta$ varies widely across countries. This suggests that, in designing policies, multilateral agencies should take into consideration "country-specific" characteristics, especially the institutional framework of the country. Indeed, a major criticism of multilateral agencies such as the World Bank is that they often utilize a "one size fits all" policy for developing countries.

Finally, our model suggests that multilateral assistance may have some inherent advantages relative to bilateral assistance. Note that, in recent years, there has been a shift from bilateral lending to multilateral lending. Multilateral lending increased from an average of $\$ 6$ billion over the period 1988-1993 to $\$ 7$ billion over the period 1994-1999. Bilateral lending declined from $\$ 8.8$ billion to $\$ 3.8$ billion over the same period. Further, since 1994, multilateral lending has surpassed bilateral lending.

We end our discussion by comparing the merits of the two developmental assistance programs. Technical assistance and loan subsidies differ in two important respects: (i) technical assistance is free to the recipient and (ii) technical assistance directly affects productivity. This suggests that technical assistance may be a better policy. Recent trends in developmental assistance indicate a shift from lending to the provision of technical assistance. For example, the share of developmental finance spent on technical assistance increased from $47 \%$ over the period 19881991 to $60 \%$ over the period $1992-1998 .^{23}$ According to our model, this policy shift will enhance investment flows.

\section{CONCLUSION}

This paper shows that when the enforcement of private contracts is limited by private creditors' ability to impose direct negative sanctions, a positive flow of foreign aid that is costly to the donor may be welfare improving for both the recipient and the donor. Such policies weaken the incentive constraint, thereby creating the potential for Pareto improvements. Key features of the model are that the poor country has a limited capital stock, $k^{p}$, attractive investment opportunities, and nontrivial default risk. By offering foreign aid, the rich country changes the poor country's payoff from default, which is directly beneficial to both countries. If the capital-poor country were to take measures to augment its own capital stock, this would reduce the donor's ability to exercise control. These trade-offs provide fertile grounds for future work.

\section{NOTES}

1. Bilateral loans are loans from developed-country governments and multilateral loans include loans from multilateral organizations such as the World Bank and Regional Development Banks (e.g., 
African Development Bank, Asian Development Bank). Developmental lending has generally been falling over time, decreasing from about $\$ 51$ billion in 1991 to $\$ 35$ billion in 1997 [cf., World Bank (2000)].

2. We define expropriation as the violation of any condition of an investment agreement: government default on foreign investment contracts or guarantees, preventing residents from honoring obligations to foreign creditors, etc.

3. See Kletzer (1994) and Eaton and Fernandez (1995) for discussions of various penalties.

4. This implication of our model is consistent with the evidence gathered by Maizel and Nissanke (1984) and Alesina and Dollar (1998).

5. Developing-country governments often use the "donor-enriching" argument as a basis to request aid. For example, President Olusegun Obasanjo of Nigeria recently remarked that "it is not because we want charity, but because we believe that it is in our creditors' strategic interests to have debt remission" [cf., Financial Times, Sept. 15, 2000].

6. We focus on risk neutrality to study the effect of "pure enforcement problems" on investment. Underinvestment is even more severe if international capital markets are used to insure consumption by risk-averse agents.

7. One can interpret $(r-\sigma)$ as the spread between the return on private investment in the poor country and LIBOR. Measures of $(r-\sigma)$ and $r$ are provided in Section 3.

8. This implies that, in the absence of default risk, the poor country can borrow the optimal amount from the rich country. Cline (1995) notes that there is no shortage of capital: The stock of financial assets in industrial countries is about $\$ 20$ trillion, but the capital flows to developing countries are about $\$ 120$ billion.

9. The proceeds from investment are consumed in the current period and debt matures each period. There is no capital accumulation. If capital accumulation occurred and the domestic stock reached the optimal level at some period $t$, the poor country's incentive problem would change. The country would lose nothing by being denied a loan in period $t+1$ and therefore would refuse to repay loans taken in period $t$. Rational investors realize this and, as a result, no lending occurs in period $t$. By backward induction, no lending occurs at all.

10. Modeling the discount factor as a function of country-specific risk, $\theta$, allows us to analyze the impact of $\theta$ on sovereign default decisions and capital flows. We provide measures of $\beta$ for selected countries in Table 2.

11. For example, loans issued by the International Development Agency, an affiliate of the World Bank carry a 35 - to 40 -year maturity, are interest free, and carry a service charge of only $0.75 \%$.

12. When $d \beta^{*} / d \gamma<0$, an increase in $\gamma$ lengthens the Case 3 interval, increasing the likelihood that the poor country will sustain the unconstrained optimal level of investment. When $d \beta^{*} / d \gamma>0$, an increase in $\gamma$ shrinks the Case 3 interval, a result that may seem problematic but is not. Recall that $\beta^{*}$ determines the equilibrium attained (constrained or unconstrained), not the level of investment. When the enforcement constraint binds, and this is the situation in which we are interested, then $\beta<\beta^{*}$. As a consequence, "constrained countries" remain constrained even if $\beta^{*}$ increases. Hence, an increase in $\beta^{*}$ does not change the equilibrium attained when (2) binds, but a loan subsidy is still desirable because it increases the level of investment $k_{c}^{*}$.

13. A number of economists and policymakers have recently argued that multilateral loans should carry higher interest rates. For example, in August 2000, the G8 recommended that the IMF increase the interest rate that it charges on its loans. The rationale behind this proposal is to discourage perpetual borrowing from the IMF. However, our analysis suggests that this policy will depress investment flows.

14. For example, in 1999 , about $\$ 16$ billion (40\% of developmental finance) was spent on Technical Assistance to developing countries [cf., World Bank (2000)].

15. Haque and Khan (1997) model technical assistance as expatriate skills that contribute to productivity. See Eaton and Gersovitz (1984) for a model in which a country loses foreign managerial skills when it expropriates foreign capital.

16. This implies that the withdrawal of technical assistance leads to an efficiency loss in production and causes output to decline by $\delta$. We provide estimates of $\delta$ in Table 2 . 
17. In addition, if monitoring is necessary, then a multilateral agency would also eliminate duplicative monitoring as is standard in delegated monitoring models.

18. The empirical studies of Schraeder et al. (1998) and Rodrik (1995) indicate that bilateral loans are not motivated by the desire to meet the economic needs of the recipient country.

19. Our argument contrasts with that of Svensson (2000) who asserts that delegating aid disbursement to an agency with less aversion to poverty will improve the welfare of the poor in the recipient country.

20. See Asiedu and Villamil (2000) for a detailed description of the risk indicators and Mauro (1995).

21. This implication of our model is consistent with the empirical findings of Collier and Dollar (1999).

22. For example, in 1998, foreign aid as a share of GNP for Sub-Saharan Africa was $4 \%$. This compares with $0.2 \%$ for Latin America and 0.3\% for East Asia [cf., World Bank (2000)].

23. This implies that the share of developmental finance spent on loan subsidies decreased from $53 \%$ to $40 \%$ over the same period.

\section{REFERENCES}

Alesina, A. \& D. Dollar (1998) Who Gives Foreign Aid to Whom and Why? NBER working paper 6612.

Asiedu, E. \& A. Villamil (2000) Discount factors and thresholds: Foreign investment when enforcement is imperfect. Macroeconomic Dynamics 4, 1-21.

Atkeson, A. (1991) International lending with moral hazard and risk of repudiation. Econometrica 59, 1069-1089.

Barro, R. \& X. Sala-i-Martin (1995) Economic Growth. New York: McGraw-Hill.

Bencivenga, V. \& B. Smith (1992) Deficits, inflation and the banking system in developing countries:

The optimal degree of financial repression. Oxford Economic Papers 44, 767-790.

Bulow, J. \& K. Rogoff (1989) Sovereign debt: Is to forgive to forget? American Economic Review 79, $43-50$.

Burnside, C. \& D. Dollar (2000) Aid policies and growth. American Economic Review 90, 847-869.

Burton, F.N. \& H. Inoue (1987) A country risk appraisal model of foreign asset expropriation in developing countries. Applied Economics 19, 1009-1048.

Cline, W. (1995) International Debt Reexamined. Washington, DC: Institute for International Economics.

Cohen, D. \& J. Sachs (1986) Growth and external debt under risk of debt repudiation. European Economic Review 30, 529-560.

Collier, P. \& D. Dollar (1999) Aid Allocation and Poverty Reduction. Mimeo, World Bank.

Diamond, D. (1984) Financial intermediation and delegated monitoring. Review of Economic Studies 51, 393-414.

Dollar, D. \& W. Easterly (1998) The Search for the Key: Aid, Investment, Policies in Africa. Mimeo, World Bank.

Eaton, J. (1993) Sovereign debt: A primer. World Bank Economic Review 7, 137-172.

Eaton, J. \& R. Fernandez (1995) Sovereign debt. In G.M. Grossman \& K. Rogoff (eds), Handbook of International Economics, vol. 3, pp. 307-328. Amsterdam: North-Holland.

Eaton, J. \& M. Gersovitz (1981) Debt with potential repudiation: Theory and estimation. Review of Economic Studies 48, 289-309.

Eaton, J. \& M. Gersovitz (1984) A theory of expropriation and deviations from perfect capital mobility. Economic Journal 94, 16-40.

Haque, N. \& M.A. Khan (1997) Institutional Development—Skill Transfer Through a Reversal of Human Capital Flight. IMF Working Paper WP/97/89.

Kletzer, K.M. (1994) Sovereign immunity and international lending. In F. van der Ploeg (ed.), The Handbook of International Macroeconomics. Oxford: Basil Blackwell. 
Krasa, S. \& A.P. Villamil (2000) Optimal contracts when enforcement is a decision variable. Econometrica 68, 119-134.

Kydland, F.E. \& E.C. Prescott (1977) Rules rather than discretion: The inconsistency of optimal plans. Journal of Political Economy 85, 474-491.

Lensink, R. \& P. Morrissey (2000) Aid instability as a measure of uncertainty and the positive impact of aid on growth. Journal of Development Studies 36, 31-49.

Maizel, A. \& M.K. Nissanke (1984) Motivation for aid to developing countries. World Development 12, 879-900.

Mauro, P. (1995) Corruption and growth. Quarterly Journal of Economics 110, 681-712.

Nunnekamp, P. \& H. Picht (1989) Default by developing countries in the 1980s: A cross-country analysis of major determinants. Welwirtschaftliches Archiv 124, 681-702.

Rodrik, D. (1995) Why Is There Multilateral lending? NBER working paper 5160.

Schraeder, P.J., S.W. Hook \& B. Taylor (1998) Clarifying the foreign aid puzzle: A comparison of American, Japanese, French and Swedish aid flows. World Politics 50, 291-320.

Smith, B. \& A. Villamil (1998) Government borrowing using bonds with randomly determined returns: Welfare improving randomization in the context of deficit finance. Journal of Monetary Economics $41,351-370$.

Svensson, J. (2000) When is foreign aid policy credible? Aid dependence and conditionality. Journal of Development Economics 61, 61-84.

Thomas, J. \& T. Worrall (1994) Foreign direct investment and the risk of expropriation. Review of Economic Studies 61, 81-108.

Williamson, S.D. (1986) Costly monitoring, financial intermediation, and equilibrium credit rationing. Journal of Monetary Economics 18, 159-179.

World Bank (2000) Global Development Finance. Washington, DC: World Bank.

Yaari, M. (1965) Uncertain lifetime, life insurance, and the theory of the consumer. Review of Economic Studies 32, 137-150.

\section{APPENDIX}

Proof of Claim 1, Parts (i) and (ii). Under loan subsidy, $B(k)$ and $G(k)$ are given by

$$
G(k)=\frac{1}{1-\beta}\left[f(k)-r(1-\gamma)\left(k-k^{p}\right)-\tau \gamma\left(k-k^{p}\right)\right]
$$

and

$$
B(k)=f(k)+\frac{\beta}{1-\beta} f\left(k^{p}\right) .
$$

In the autarky equilibrium, $B(k)$ cuts $G(k)$ at $k^{p}$ from below. This implies that $B^{\prime}\left(k^{p}\right)<$ $G^{\prime}\left(k^{p}\right)$ and $\beta f^{\prime}\left(k^{p}\right)<r(1-\gamma)+\gamma \tau$. Thus, the smallest discount factor required to attract foreign investment, $\underline{\beta}$, is given by

$$
\underline{\beta}\left(k^{p}, r, \gamma, \tau\right)=\frac{r(1-\gamma)+\gamma \tau}{f^{\prime}\left(k^{p}\right)} .
$$

Further, $k_{u}^{*}$ is self-enforcing if and only if $B\left(k_{u}^{*}\right) \leq G\left(k_{u}^{*}\right)$. This implies that $k_{u}^{*}$ is selfenforcing if and only if $\beta \geq \beta^{*}$, where $\beta^{*}$ is defined by

$$
\beta^{*}\left(r, k^{p}, \gamma, \tau\right)=\frac{[r(1-\gamma)+\tau \gamma]\left(k_{u}^{*}-k^{p}\right)}{f\left(k_{u}^{*}\right)-f\left(k^{p}\right)} .
$$


When the incentive constraint binds, $k_{c}^{*}$ satisfies

$$
\beta\left[f\left(k_{c}^{*}\right)-f\left(k^{p}\right)\right]-\left(k_{c}^{*}-k^{p}\right)[r(1-\gamma)+\tau \gamma]=0
$$

and

$$
y_{c}^{*}=\frac{1}{1-\beta}\left[f\left(k_{c}^{*}\right)-r(1-\gamma)\left(k_{c}^{*}-k^{p}\right)-\tau \gamma\left(k_{c}^{*}-k^{p}\right)\right]
$$

Differentiating (A.1), (A.2), (A.3), and (A.4) with respect to $\gamma$ and $\tau$ yields

$$
\begin{aligned}
\frac{d \underline{\beta}}{d \gamma} & =-\frac{(r-\tau)}{f^{\prime}\left(k^{p}\right)}, \quad \frac{d \underline{\beta}}{d \tau}=\frac{\gamma}{f^{\prime}\left(k^{p}\right)}, \\
\frac{d k_{c}^{*}}{d \gamma} & =-\frac{(r-\tau)\left(k_{c}^{*}-k^{p}\right)}{\beta f^{\prime}\left(k_{c}^{*}\right)-[r(1-\gamma)+\tau \gamma]}, \\
\frac{d k_{c}^{*}}{d_{\tau}} & =\frac{\gamma\left(k_{c}^{*}-k^{p}\right)}{\beta f^{\prime}\left(k_{c}^{*}\right)-[r(1-\gamma)+\tau \gamma]} ; \\
(1-\beta) \frac{d y_{c}^{*}}{d \tau} & =\left\{f^{\prime}\left(k_{c}^{*}\right)-[r(1-\gamma)+\gamma \tau]\right\} \frac{d k_{c}^{*}}{d \tau}-\gamma\left(k_{c}^{*}-k^{p}\right), \\
{[1-\beta) \frac{d y_{c}^{*}}{d \gamma} } & =\left\{f^{\prime}\left(k_{c}^{*}\right)-[r(1-\gamma)+\gamma \tau]\right\} \frac{d k_{c}^{*}}{d \gamma}+\left(k_{c}^{*}-k^{p}\right)(r-\tau), \\
{\left[f\left(k_{u}^{*}\right)-f\left(k^{p}\right)\right] \frac{d \beta^{*}}{d \tau} } & =-\left\{\beta^{*} f^{\prime}\left(k_{u}^{*}\right)-[r(1-\gamma)+\tau \gamma]\right\} \frac{d k_{u}^{*}}{d \tau}+\gamma\left(k_{u}^{*}-k^{p}\right), \\
&
\end{aligned}
$$

Note that $B(k)$ cuts $G(k)$ at $k_{c}^{*}$ from below and therefore $\left\{\beta f^{\prime}\left(k_{c}^{*}\right)-[r(1-\gamma)+\right.$ $\tau \gamma]\}<0$. Further, since $d k_{c}^{*} / d \tau<0$, the sign of the right-hand side of (A.6) is unclear. A similar analysis holds for $d \beta^{*} / d \gamma$.

Proof of Claim 1, Parts (iii) and (iv). Recall that a country is in the autarky equilibrium if $\beta \in(0, \beta)$ and the constrained equilibrium if $\beta \in\left(\beta, \beta^{*}\right)$. Therefore, a loan package $\bar{w}=w(\bar{\tau}, \bar{\gamma})$ that lowers $\beta$ to a point where $\beta=\beta\left(r, k^{p}, \bar{w}\right)=[r(1-\bar{\gamma})+\bar{\tau} \bar{\gamma}] / f^{\prime}\left(k^{p}\right)$ will eliminate the autarky equilibrium. Similarly, a loan package $w^{*}=w\left(\tau^{*}, \gamma^{*}\right)$ that lowers $\beta^{*}$ to a point where $\beta=\beta^{*}\left(r, k^{p}, w^{*}\right)$ will move the equilibrium from constrained to unconstrained.

Proof of Proposition 1. For lending to occur, $\beta \geq \underline{\beta}$; otherwise the poor country will default. Therefore, the loan package $\hat{w}=w(\hat{\gamma}, \hat{\tau})$ should lower $\beta$ to the point where $\beta \geq \beta\left(r, k^{p}, \hat{w}\right)=[r(1-\hat{\gamma})+\hat{\tau} \hat{\gamma}] / f^{\prime}\left(k^{p}\right)$, thereby eliminating the incentive to default [see the proof of Claim 1(i) for the derivation of $\beta$ ]. To prove Part (ii), note that $U^{r}(w)=$ $[(r-\sigma)-\gamma(r-\tau)]\left(k_{c}^{*}-k^{p}\right)+\bar{u}^{r}$, where $\bar{u}^{r}$ is the utility under autarky. The result follows from the fact that $U^{r}(\hat{w})>\bar{u}^{r}$ if and only if $(r-\sigma)>\hat{\gamma}(r-\hat{\tau})$.

Solution to Problem 3. The first-order conditions are given by

$$
\begin{aligned}
& {[(r-\sigma)-\gamma(r-\tau)] \frac{d k_{c}^{*}}{d \gamma}-(r-\tau)\left(k_{c}^{*}-k^{p}\right)=0,} \\
& {[(r-\sigma)-\gamma(r-\tau)] \frac{d k_{c}^{*}}{d \tau}+\gamma\left(k_{c}^{*}-k^{p}\right)+\lambda=0,} \\
& \tau \lambda=0,
\end{aligned}
$$


where $k_{c}^{*}=k_{c}^{*}(\tau, \gamma)$ satisfies $B\left(k_{c}^{*}\right)=G\left(k_{c}^{*}\right)$ and $\lambda$ is the Lagrange multiplier. Substituting (A.5) in (A.7) and (A.8) yields $\lambda=0$. This implies that $\tilde{\gamma}$ and $\tilde{\tau}$ are uniquely determined by (A.7) and (A.8).

Proof of Claim 2, Part (i). Under technical assistance, $G(k)$ and $B(k)$ are given by

$$
G(k)=\frac{1}{1-\beta}\left\{[1+\delta(\alpha)] f(k)-r\left(k-k^{p}\right)\right\}
$$

and

$$
B(k)=[1+\delta(\alpha)] f(k)+\frac{\beta}{1-\beta} f\left(k^{p}\right) .
$$

Note that $B\left(k^{p}\right)<G\left(k^{p}\right)$. Hence there exists a $\bar{k}>k^{p}$ such that $B(k)<G(k)$ for $k \in\left(k^{p}, \bar{k}\right)$. This implies that, for $k \in\left(k^{p}, \bar{k}\right)$, no expropriation occurs and therefore some level of foreign investment, $\left(\bar{k}-k^{p}\right)$, is sustainable.

Proof of Claim 2, Part (ii). Under technical assistance policy, an investment plan, $k$, is self-enforcing if and only if $B(k) \leq G(k)$. Thus, $k$ is self-enforcing if

$$
0<\frac{r\left(k-k^{p}\right)}{[1+\delta(\alpha)] f(k)-f\left(k^{p}\right)} \leq \beta<1 .
$$

Substitute $k=k_{u}^{*}$. Then, $k_{u}^{*}$ is self-enforcing if and only if $\beta \geq \beta^{*}$, where $\beta^{*}$ is defined by

$$
\beta^{*}=\frac{r\left[k_{u}^{*}-k^{p}\right]}{[1+\delta(\alpha)] f\left(k_{u}^{*}\right)-f\left(k^{p}\right)}
$$

When the incentive constraint binds, $k_{c}^{*}$ satisfies

$$
\beta\left\{[1+\delta(\alpha)] f\left(k_{c}^{*}\right)-f\left(k^{p}\right)\right\}-r\left(k_{c}^{*}-k^{p}\right)=0
$$

and

$$
y_{c}^{*}=\frac{1}{1-\beta}\left\{[1+\delta(\alpha)] f\left(k_{c}^{*}\right)-r\left(k_{c}^{*}-k^{p}\right)\right\} .
$$

Differentiating (A.9), (A.10), and (A.11) with respect to $\alpha$ yields

$$
\begin{gathered}
\frac{d k_{c}^{*}}{d \alpha}=-\frac{\beta f\left(k_{c}^{*}\right) \delta^{\prime}(\alpha)}{\beta[1+\delta(\alpha)] f^{\prime}\left(k_{c}^{*}\right)-r}, \\
(1-\beta) \frac{d y_{c}^{*}}{d \alpha}=\left\{[1+\delta(\alpha)] f^{\prime}\left(k_{c}^{*}\right)-r\right\} \frac{d k_{c}^{*}}{d \alpha}+\delta^{\prime}(\alpha) f\left(k_{c}^{*}\right), \\
\left\{[1+\delta(\alpha)] f\left(k_{u}^{*}\right)-f\left(k^{p}\right)\right\} \frac{d \beta^{*}}{d \alpha}=-\left\{\beta^{*}[1+\delta(\alpha)] f^{\prime}\left(k_{u}^{*}\right)-r\right\} \frac{d k_{u}^{*}}{d \alpha}-\beta^{*} f\left(k_{u}^{*}\right) \delta^{\prime}(\alpha) .
\end{gathered}
$$

When the enforcement constraint binds, $B(k)$ cuts $G(k)$ at $k_{c}^{*}$ from below and therefore $\left[\beta(1+\delta) f^{\prime}\left(k_{c}^{*}\right)-r\right]<0$. The sign of the right-hand side of (A.12) is unclear since $d k_{u}^{*} / d \alpha>0$ and $\delta^{\prime}(\alpha)>0$.

Proof of Claim 2, Part (iii). Choose $\hat{\alpha}$ such that $\beta=\beta^{*}\left(r, k^{p}, \hat{\alpha}\right)$. 
Proof of Proposition 3. The utility of the rich country under technical assistance is

$$
U^{r}(\alpha)=\left[(r-\sigma)\left(k_{c}^{*}-k^{p}\right)-\sigma \alpha\right]+\bar{u}^{r} .
$$

The result follows from the fact that $U^{r}(\alpha)>\bar{u}^{r}$ if and only if $\alpha \sigma<(r-\sigma)\left(k_{c}^{*}-k^{p}\right)$.

Solution to Problem 4. Problem 4 is solved by $\tilde{\alpha}$ if it satisfies the first-order condition:

$$
(r-\sigma) \frac{d k_{c}^{*}}{d \alpha}-\sigma=0
$$

where $k_{c}^{*}=k_{c}^{*}(\alpha)$ and $B\left(k_{c}^{*}\right)=G\left(k_{c}^{*}\right)$. 